\title{
Emociones y discurso público: una mirada de género a la retórica política afectiva $^{1}$
}

Emotions and public discourse: a gender look at affective political rhetoric

\author{
JULEN ORBEGOZO TERRADILLOS \\ UNIVERSIDAD DEL PAÍS VASCO \\ HTTPS://ORCID.ORG/0000-0002-2959-4397
}

AINARA LARRONDO URETA

UNIVERSIDAD DEL PAÍS VASCO

HTTPS://ORCID.ORG/0000-0003-3303-4330

AMAIA LANDABURU CORCHETE

UNIVERSIDAD DEL PAÍS VASCO

HTTPS://ORCID.ORG/0000-0002-0014-9054

RESUMEN: Esta investigación se centra en el estudio de la emotividad discursiva en el ámbito institucional desde la perspectiva de género. Este estudio parte de la necesidad de profundizar en aquellos factores y estrategias de la Comunicación Política que pueden impulsar una transformación discursiva y, por ende, una evolución social y democrática (Arias Maldonado, 2016). Específicamente, el artículo examina el nuevo papel de las emociones en la esfera pública desde una aproximación centrada en un estudio de caso sobre las personas electas en los órganos legislativos de la Comunidad Autónoma Vasca (CAV). El estudio empírico relaciona dos elementos infrarrepresentados tradicionalmente en el espacio público-político: las mujeres y las emociones o los sentimientos personales. Este análisis utiliza la encuesta digital como técnica de investigación. Los resultados permiten observar las diferencias significativas entre mujeres electas y hombres electos en relación a la manifestación de sus emociones, así como indagar acerca de los motivos y causas que llevan a ambos

\footnotetext{
${ }^{1}$ Este artículo forma parte de la producción académica de Gureiker (IT1112-16), Grupo Consolidado del Sistema Universitario Vasco, UPV/EHU.
} 
géneros a excluir las emociones en sus discursos. Se concluye que el ejercicio de contención es recurrente por ser, la demostración de afectos, sinónimo de debilidad. Además, las mujeres encuestadas muestran un mayor convencimiento de que una mayor subjetividad emocional contribuye a mejorar el sistema político.

Palabras clave: comunicación política, emociones, perspectiva de género, mujeres en política, esfera pública, giro afectivo.

ABSTRACT: This research focuses on the study of discursive emotionality in the institutional sphere from a gender perspective. This study is thus based on the need to delve deeper into those factors and strategies of political communication that can drive a discursive transformation and, therefore, a social and democratic evolution (Arias Maldonado, 2016). Specifically, the article examines the new role of emotions in the public sphere, from an approach centred on a case study of people elected to the legislative bodies of the Basque Autonomous Community (BAC). The empirical study draws a line that relates two elements underrepresented in the public-political space: women and emotions or personal feelings. This analysis uses the digital survey as a research technique. The results allow us to observe the significant differences between elected women and elected men in relation to the manifestation of their emotions, as well as to investigate the motives and causes that lead both genders to exclude emotions in their speeches. It is concluded that the exercise of containment of affections is recurrent because the demonstration of emotions is synonymous with weakness. In addition, the women surveyed show a greater conviction that greater emotional subjectivity contributes to improving the political system.

Key words: political communication, emotions, gender perspective, woman in politics, public sphere, affective turn.

\section{INTRODUCCIÓN: MUJERES, EMOCIONES Y DISCURSO PÚBLICO}

Lo privado y lo público constituyen una condición estructural que articula las sociedades jerarquizando los espacios (Amorós, 1994). El sistema social patriarcal ha reservado tradicionalmente un mayor protagonismo a las mujeres en el espacio privado, adjudicando a los hombres las actividades socialmente más estimadas o con mayor reconocimiento bajo la mirada pública. Tal y como recuerda Ana de Miguel Álvarez (2000), en las sociedades occidentales se ha construido una dicotomía entre la esfera pública y la privada, adjudicando dichos espacios sociales según el género y la jerarquización valorativa de dichos espacios. En ese sentido, a la identidad femenina se la ha ubicado tradicionalmente en la citada esfera privada junto a elementos como los sentimientos o los afectos (ver Tabla 1). 
Tabla 1. Propuesta de diferenciación entre la esfera pública y la privada y sus respectivos elementos

\begin{tabular}{|c|c|}
\hline Esfera pública & Esfera privada \\
\hline Masculino & Femenino \\
\hline Universal-imparcial & Particular-afectos \\
\hline Cultura & Naturaleza \\
\hline Libertad & Necesidad \\
\hline Mente - Producción de ideas & Cuerpo - Producción de cuerpos \\
\hline Razón - Entendimiento & Pasión - Sentimientos \\
\hline Ética de la justicia & Ética del cuidado \\
\hline Competitividad & Caridad - Beneficencia \\
\hline Hacer & Ser \\
\hline Productividad - Trabajo & Improductividad - No Trabajo \\
\hline Los iguales - Individuos o ciudadanos & Las idicas: madres-esposas \\
\hline
\end{tabular}

Fuente: De Miguel Álvarez (2000)

Esta adjudicación de espacios en las sociedades occidentales y la separación clásica entre lo público y lo privado es uno de los impedimentos que dificulta el avance paritario. De hecho, la lucha igualitaria de género ha buscado desde su primer movimiento organizado a comienzos del siglo pasado romper con el supuesto «orden social natural» (Velázquez, 2017) y, tal y como explica Alba Carosio (2007), construir una sociedad fundada en un nuevo tipo de poder y convivencia humana.

Con todo, el siglo XXI ha visto consolidar medidas orientadas a superar la anteriormente citada dicotomía entre lo público y lo privado $\mathrm{y}$, con ello, la infrarepresentación sistemática y tradicional de las mujeres en los ámbitos de autoridad y de toma de decisiones en todo el mundo (Rubio Marín, 2020). Este avance hacia una esfera pública y política más igualitaria o paritaria se ha desarrollado mayoritariamente desde una perspectiva cuantitativa de género.

El avance no ha sido fácil y ha obligado a superar el arquetipo del sujeto políticoconceptual que ha interactuado durante siglos en los espacios de representación. Dicho sujeto se ha manifestado tradicionalmente a través de su propia retórica en la esfera pública. Mary Beard, en su obra Women and Power (2017), explica que el citado «orden social natural» ha contribuido a que en el seno de la cultura occidental hayamos pasado miles de años vetando a las mujeres en el ágora pública y en la retórica política, a través de mecanismos instaurados para silenciar su voz:

En la Antigüedad, la oratoria y el discurso público no eran simplemente actividades en que las mujeres no tenían participación, sino que eran prácticas y habilidades exclusivas que definían la masculinidad como género. Convertirse en un hombre suponía reivindicar el derecho a hablar, porque el discurso público era un atributo definitorio de la virilidad.

(Beard, 2017: 27)

De hecho, las visiones clásicas de autores como Homero u Ovidio, trasladadas en el Renacimiento, proveyeron, durante el siglo pasado, de poderosos patrones de pensamiento sobre el tipo de discurso público más oportuno y efectivo, inspirando los manuales de oratoria y, por ende, los discursos de los representantes públicos (Beard, 2017). Dichos manuales contribuyeron a definir una determinada «ontología de la exclusión» del debate público, al definir quién debía hablar en público y cómo lo debía 
hacer; o cómo debía hablar y qué artefactos retórico-persuasivos debía emplear el «hombre público» (Sennet, 1977) en sus disertaciones políticas.

Tomando como punto de partida esos importantes antecedentes, el aludido avance en la representación paritaria en la esfera pública y política viene precedido, en gran medida, por décadas de trabajo de concienciación del feminismo. Autoras como Alexander, Bolzendahl, Jalalzai (2018) o Sundström et al. (2017) sintetizan esta idea bajo la expresión «empoderamiento político de las mujeres».

El «empoderamiento», pues, ha sido considerado un concepto clave en la teoría feminista liberal y las relaciones heteronormativas, las cuales, en tanto que relaciones de poder, han condicionado tradicionalmente un determinado «empoderamiento» para las mujeres, también en el ámbito público de los parlamentos. La agenda ideológica ya establecida hace que se espere de las mujeres parlamentarias un «empoderamiento»a través de determinado tipo de discurso político-institucional, de corte racional, como significante del modo en el que las relaciones de género han cambiado dentro y fuera de la política, al conseguir acercar los roles de género e integrar completamente a la mujer en la esfera pública, en los mismos términos que el hombre.

Pero una buena parte de la teoría feminista ha rechazado la falsa dicotomía entre racionalidad e irracionalidad. De hecho, como señala Frost (2019), el hecho de que las mujeres sean consideradas «emocionales» en algunos contextos ofrece una buena base para discutir el rol que las emociones juegan en el modo en el que otorgamos sentido a nuestras identidades y las identidades de otros. Así, es posible entender cómo la mujer se construye emocionalmente como categoría, es decir, cómo se identifica como mujer a partir de esta categoría.

Así, la nueva esfera pública, repensada por Peñamarín (2016) a partir de las ideas de H. Arendt, se define como un nuevo espacio común de diversidad:

En la reflexión de Arendt el reconocimiento de la diversidad es necesario para que el poder sustituya a la violencia. Si la violencia es (...) la imposición de una visión única que acalla a todas las otras posibles, el poder, por el contrario, es la capacidad de expresar una convicción, una perspectiva, un interés en la esfera pública respetando las voces y visiones imprescindibles de quienes están en desacuerdo.

(Peñamarín, 2016: 41)

En ese sentido, el citado enfoque propone «situar la diversidad, el conflicto y las emociones en el centro de la reflexión sobre la vida social y política» (Peñamarín, 2016: 36).

Desde otras perspectivas, como las de las teorías poscoloniales, los estudios subalternos centraron el interés de sus investigaciones en documentar la experiencia de las poblaciones excluidas, en particular de «los colectivos excluidos de las narrativas hegemónicas de la historia y la modernidad» (Connell, 2008: 214). La pensadora feminista Gayatri Chakravorty Spivak (1998) elabora una crítica en torno a esta exclusión en la representación o silenciamiento con la noción de «violencia epistémica», e insiste en la necesidad de «considerar los márgenes del discurso (o lo que podríamos denominar también 'el centro silencioso o silenciado') de un circuito marcado por una violencia epistémica» (Spivak, 1998: 15), donde están las voces de las mujeres subalternas.

En ese contexto, el objeto e interés central de este trabajo de investigación es, precisamente, observar conjuntamente y relacionar dos elementos relegados tradicionalmente del citado espacio público-político: las mujeres y las emociones o los sentimientos personales.

El interés académico por esta estrecha relación no es casual, entre otras cuestiones, porque la comunicación política puede obtener provecho retórico del uso de las emociones, si bien hasta la fecha esta posibilidad ha sido aún escasamente explotada 
(Richards, 2010). De hecho, como estrategia retórica, el uso de las emociones todavía sobresale en el ámbito de la comunicación política tradicional, poco proclive a la expresión de cualquier contenido vinculado a lo personal en términos afectivos. La relación actual de la política y los políticos con la manifestación de sus sentimientos supone, por ello, un claro foco de interés investigador en nuestros días (Marcus, 2000; Stanyer, 2013).

Por otro lado, la «emocionalización» de los discursos políticos aporta un claro punto de conexión con la ciudadanía y, según se ha demostrado, aquellos políticos que se muestran más emocionales o que expresan de manera más abierta sus sentimientos empatizan mejor con el electorado (Breeze, 2019: 27).

Este interés por los afectos en política resulta todavía más evidente si tenemos en cuenta que la asimilación de las emociones en el discurso político representa un claro factor de regeneración democrática (Innerarity, 2019). Una renovación que se acompaña de otros cambios importantes a la luz de este artículo, como la creciente feminización de la política.

\subsection{ESTADO DE LA CUESTIÓN}

El estudio de las emociones en un contexto de política parlamentaria como el que desarrolla este artículo parte de la necesidad de profundizar en aquellos factores y estrategias de la comunicación política que pueden impulsar en el contexto actual una transformación discursiva y, por ende, una transformación social y democrática (Arias Maldonado, 2016; Orbegozo y Larrondo, 2019). Entre dichos factores, este trabajo pone el foco en el discurso emotivo o afectivo y sus efectos, un objeto abordado tradicionalmente por la psicología discursiva. La teorización vinculada al «giro afectivo» en política equipara las emociones a los afectos y sentimientos (Arias Maldonado, 2016). Desde un punto de vista general, teóricos del «giro afectivo» en las ciencias sociales establecen la siguiente relación para indicar que se trata de dos conceptos diferentes, pero interdependientes a partir de su componente «personal»: el afecto es considerado algo sensorial o corpóreo, precognitivo o no consciente, y pre-personal; la emoción alude a un constructo cultural o social que permite una interpretación individual del afecto (Lara y Domínguez, 2013). Por su parte, el sentimiento es algo personal y biográfico (Massumi, 1996).

Si bien adolecen aún de mayor recorrido, no cabe duda que los estudios vinculados a la emocionalización de la comunicación política y pública se ven influidos desde hace años por el llamado "giro afectivo» de las ciencias sociales -en la terminología anglosajona, affective turn (Clough y Halley, 2007)-, concepto también abordado desde perspectivas feministas críticas como la presentada por Macón (2014) o Lara y Enciso (2013). Con todo, el «giro afectivo» se ha convertido, de hecho, en el principal indicador del interés científico por entender las causas y consecuencias de la emocionalización que vive la vida pública y el sujeto (Lara y Domínguez, 2013).

Cabría apuntar aquí que este «giro» y el interés por los discursos emocionales en el ámbito público-político son dependientes del actual contexto tecnologicista, en el que la expresión de las emociones se ve facilitada por el uso de los dispositivos conectados, todo ello en una cultura mediática híper-afectiva en red (Kay, 2019). La literatura sobre el tema hace referencia a una «sociedad afectiva» en la que los medios de masas promueven la emocionalización de la esfera pública, hasta el punto de que la «emocionología» parece sustituir, en ocasiones, a la «ideología» tradicional (Arfuch, 2016). En ese sentido, en años recientes ha habido eventos digitales rupturistas como el 
movimiento \#MeToo (Orgad y Gill, 2019), que han contribuido a romper el silenciamiento de emociones históricamente contenidas como la rabia de las mujeres.

Se entiende así que destaquen mayoritariamente los análisis discursivos políticos a partir de sentimientos y afectos en el entorno de las redes sociales. En contraste, el análisis de la emotividad de otros discursos políticos específicos y, más concretamente, el análisis de la emotividad discursiva desde la perspectiva de género en el ámbito parlamentario resulta mucho más limitado.

A este respecto, es de obligada referencia el estudio de Alcaide, Carranza y Fuentes Rodríguez (2016) sobre el Parlamento andaluz, o el de Iñigo Mora (2007) sobre el Congreso español. Ambos análisis evidencian el uso de la emoción por parte de los parlamentarios como un recurso argumentativo con diferentes fines (persuadir, atacar al oponente, expresar proximidad respecto a los problemas de la ciudadanía, crear una identidad distintiva y, en general, para reforzar el discurso). En la misma línea, pero desde una perspectiva complementaria, el análisis de Álvarez Benito e Iñigo Mora (2016) se centra en los aspectos comunicativos no verbales que acompañan a la expresión de emociones en el contexto parlamentario, caso del contacto visual, la expresión facial, la postura o el movimiento corporal.

Es cierto que, en tanto que práctica discursiva, la emoción se vincula de una manera más habitual a los discursos de tipo informal, generados habitualmente en el contexto de esferas más íntimas y sentimentales. Considerar la emoción como una práctica discursiva en el ámbito de discursos formales vinculados a los Parlamentos resulta por ello, cuanto menos, un objeto investigador novedoso y de utilidad. Añadir la perspectiva de género conlleva, asimismo, un enfoque enriquecedor. De hecho, de la misma manera que la emoción ha sido tradicionalmente vinculada al ámbito informal frente al formal (esfera pública), la emoción y lo subjetivo también han sido vinculados mayoritariamente al género femenino ${ }^{2}$ (Fischer, 2000; Lupton, 1998), como se ha hecho con lo racional vinculado al género masculino (Holmes, 2004).

En ese contexto, durante los últimos años se ha incrementado el esfuerzo del ámbito académico a investigar y comprender el papel de las emociones en la dinámica institucional y política (Fernandes et al., 2020), ya que según algunas autoras como Gravante y Poma (2015) o Lara y Enciso (2013) los afectos o las emociones pueden promover transformaciones sociales y políticas.

Así, conviene, también, reproducir parte de la reflexión feminista en torno a los afectos, los sentimientos y las emociones. No en vano, el concepto de emoción se ha redefinido a lo largo del tiempo (Butler, 1997) y a la luz de los postulados que fusionan emoción y cognición ${ }^{3}$. Como confirman Solana y Luz (2020), el feminismo de corte marxista y socialista criticó los repertorios afectivos por su utilidad alienadora, al asociar feminidad, domesticidad y reproducción. Esta crítica a los afectos servía así de trasfondo de la reivindicación sobre la racionalidad de las mujeres $\mathrm{y}$, por ende, sobre sus capacidades como seres humanos. La teoría feminista liberal se encargaría en el contexto de la segunda ola (Women's Lib) de impulsar estos debates críticos en torno a las

\footnotetext{
${ }^{2}$ Una de las autoras de referencia para entender y poner en contexto el concepto de «emoción» y los estereotipos de género es Agneta Fischer, con obras como «Gender and Emotion» (2000).

${ }^{3}$ De ser vinculada a la irracionalidad, la emoción pasó hace décadas a definirse a partir de su cualidad racional y subjetiva. Ello implica desligar las emociones de la idea de irracionalidad, asociándolas a determinadas capacidades, como la gestión emocional y, por ende, a determinadas estrategias, como su uso con fines específicos, como la persuasión. Existen así en torno a los afectos, sentimientos y emociones postulados anti-intencionales y otros que postulan una «racionalidad de las emociones», según la cual, la emoción depende de una determinada percepción de la realidad y ésta, a su vez, depende del juicio o de manera de valorar dicha realidad (Solomon,1973).
} 
dicotomías emoción y razón, hombre-mujer, privado-público, naturaleza-cultura, etc., incidiendo en la crítica a la naturalización del ámbito privado y doméstico como ámbito ideal para la emocionalización y, por ende, para la mujer (Ahmed, 2015; Friedan, 2009).

Más recientemente, la influencia del giro afectivo ha llevado al feminismo a teorizar las emociones con varios objetivos, entre otros, abordar su potencial a la hora de generar conocimiento y transformar la sociedad desde lo político, dando lugar a «nuevos modos de sentir que (...) habiliten formas de intervención política» (Solana y Luz, 2020: $6)$.

A este respecto, la teoría feminista ha rechazado aquellas emociones que pueden contribuir a la estereotipación y asunción de un sujeto femenino universal, como la empatía (Haraway, 1995), sin que ello haya impedido al feminismo reconocer que las emociones tienen potencial político, que existen ciertos repertorios necesarios y útiles porque hay diferentes maneras de hacer política, siendo una de ellas la política creada y comunicada desde los afectos y los sentimientos (Gorton, 2007).

\section{OBJETIVOS, HIPÓTESIS Y METODOLOGÍA DE ESTUDIO}

La correlación de fuerzas entre la esfera pública y privada ha variado con el tiempo, difuminando sus límites (Thompson, 2011). Al mismo tiempo, el incremento de mujeres que interactúan en el espacio político coincide con la existencia de una mayor presencia de las emociones personales en el discurso público y político, en comparación con épocas precedentes. Es decir, cada vez hay más mujeres políticas y cada vez las personas que participan en política, mujeres y hombres, se presentan como sujetos que sienten, construyendo relatos sobre aquello que sienten, en primera persona. Cada vez más, la retórica política parte de las subjetividades sensoriales o afecciones parciales de los individuos que interactúan en el sistema.

Partiendo de estas premisas, este artículo examina el nuevo papel de las emociones en la esfera pública y, en especial, en la retórica política desde la perspectiva de género y a partir de una aproximación centrada en un estudio de caso sobre las personas electas en los órganos legislativos de la Comunidad Autónoma Vasca (CAV). La población aludida en este estudio la conforman 228 personas electas: 75 parlamentarias y parlamentarios del Parlamento Vasco y 153 miembros electos de la Juntas Generales de Araba, Bizkaia y Gipuzkoa.

\subsection{OBJETIVOS DE LA INVESTIGACIÓN E HIPÓTESIS}

Este trabajo trata de cubrir un vacío existente en los estudios actuales sobre comunicación política. Metodológicamente, el estudio trata también de aportar un procedimiento de interés para examinar la relación directa entre el género y el uso de las emociones en el discurso o la retórica política. Más allá de las limitaciones propias de la aproximación al problema a partir de la metodología del estudio de caso, los resultados que presenta este artículo pueden resultar de interés para estudios similares.

De esta forma, este estudio tiene como objetivo principal analizar el uso de las emociones en la retórica política desde la perspectiva subjetiva de quien las usa en primera persona. Ello permitiría alcanzar otro objetivo derivado, como el estudio del grado de relación entre el género y las opiniones de las personas electas en torno a las emociones como recurso retórico en el discurso público.

Los objetivos que guían la investigación pueden ser también formulados a partir de los siguientes interrogantes: ¿Cómo se posicionan ante el uso de las emociones en su discurso público los y las parlamentarias vascas? ¿Hay diferencias entre mujeres electas 
y hombres electos en el empleo de emociones en la retórica política y el posicionamiento en torno a esta cuestión?

A partir de estos objetivos centrales, el estudio ha partido de una doble hipótesis:

1. Las personas electas en las cámaras legislativas vascas tienden, en su mayoría, a reprimir sus emociones en sus discursos públicos debido a la presión de terceros y a la consideración de que las emociones deben excluirse del sistema político (H1).

2. Las mujeres electas vascas manifiestan más sus emociones en su actividad política que sus colegas masculinos, y muestran una visión más positiva en cuanto a su función para regenerar la democracia $(\mathrm{H} 2)$.

\subsection{TÉCNICAS PARA LA RECOGIDA DE DATOS}

Para responder a los objetivos señalados se llevó a cabo un diseño metodológico sustentado en la encuesta digital de respuesta directa como técnica de investigación. Ésta ha sido hasta la fecha ampliamente utilizada como método científico, porque permite obtener y elaborar datos de modo rápido y eficaz (Casas, Repullo y Donado, 2003). La investigación responde a la planificación tradicional de esta técnica de análisis: tras identificar el problema, se determinan las hipótesis, las variables y se diseña el cuestionario para organizar posteriormente el trabajo de campo, gracias al cual se obtienen los datos de los que extraer los resultados que serán analizados e interpretados (Santesmases, 2005).

El trabajo de campo para la aplicación de la encuesta se organizó en dos tiempos: por una parte, se remitió un cuestionario con preguntas cerradas a todos los miembros de los cuatro órganos legislativos del País Vasco, el Parlamento Vasco y las Juntas Generales de Araba, Bizkaia y Gipuzkoa. Por otra parte, en un segundo contacto con las personas que respondieron al primer cuestionario y se mostraron dispuestas a colaborar en mayor profundidad, se envió un segundo sondeo con preguntas abiertas para obtener un enfoque más cualitativo del objeto analizado. Esta segunda encuesta incluía tres preguntas e invitaba a las personas participantes a que se explayaran libremente y desarrollaran algunos aspectos como, por ejemplo, los motivos por los que sienten la necesidad de disimular o reprimir sus sentimientos; o el tipo de pensamiento que les invade a la hora de reprimir sentimientos personales.

La decisión de dividir el cuestionario en dos fases consecutivas responde al interés por obtener en el estudio la participación de dos perfiles diferentes: uno constituido por participantes ligeramente interesados que otorgan un tiempo muy limitado al cuestionario; y otro con participantes con una mayor implicación y, por tanto, más predispuestos a aportar datos específicos y reflexiones más profundas. El estudio ha buscado así en todo momento poder contar con la información proporcionada por ambos tipos de perfiles.

Para detectar posibles errores en la formulación y para determinar la pertinencia de las preguntas a la hora de conseguir los objetivos de la investigación, se testó la primera encuesta con un total de veinte participantes. Este pretest o cuestionario piloto (Marín, 1985) dio paso al primer cuestionario definitivo que contempló un total de dieciocho preguntas o ítems de análisis, organizados en torno a los siguientes tres bloques temáticos:

1. Ámbito personal: datos personales, en aras de clasificar la muestra con variables como el partido político, la edad, la trayectoria política y el sexo.

2. Cuestiones relacionadas con la propia manifestación de las emociones en primera persona. 
3. Cuestiones generales sobre la presencia de las emociones personales en el discurso público.

El cuestionario combinó preguntas de opción múltiple de una sola respuesta (en algunos casos, «sí» o «no»; y en otros, «sí, siempre», «sí, habitualmente», «ocasionalmente», «no, nunca» $\mathrm{o}$ «no sabe/no contesta»); preguntas de varias respuestas (pudiendo elegir una o más afirmaciones planteadas por el equipo investigador); preguntas de opción múltiple de tipo matriz (pudiendo otorgar un grado de satisfacción en forma de puntuación a las afirmaciones planteadas); o preguntas de escala de clasificación, para clasificar un atributo o una características determinada relacionada con el objeto de la investigación. Las preguntas, concretamente, giraron en torno a la represión de las emociones en sus discursos, a la percepción personal sobre la opinión que suscita en su entorno la retórica emocional, a los distintos registros políticos y el «encaje» de las emociones en cada uno de ellos, el pasado y el futuro del uso de las emociones en el discurso público en general, etc.

\subsection{CARACTERÍSTICAS DE LA MUESTRA}

La muestra final de participantes en el estudio quedó conformada por 129 parlamentarias, parlamentarios, junteras y junteros de las cuatro cámaras legislativas vascas ya señaladas, siendo el número total de personas electas en las cuatro cámaras 228 , de las cuales 115 son hombres y 113 mujeres. De las 129 personas participantes, 73 participan en la parte cualitativa de la investigación conformada por las preguntas abiertas.

El cuestionario realizado con el software profesional Encuestafacil.com se remitió a estos representantes a través del responsable del gabinete o departamento de comunicación de cada grupo parlamentario y juntero. El trabajo de campo tuvo lugar entre el 13 de enero de 2020 y el 14 de mayo de 2020.La comunicación directa de los investigadores con el responsable de comunicación de cada grupo/partido político a través de teléfono, correo electrónico y mensajería (Whatsapp) resultó esencial para conseguir la implicación personal de las y los representantes políticos y alcanzar los objetivos del estudio.

Por lo que se refiere a las características de la muestra, las más participativas, a tenor de su número en las cámaras legislativas, fueron las personas electas de la coalición soberanista y de izquierdas, Euskal Herria Bildu (EH Bildu), y el Partido Socialista de Euskadi-Euskadiko Ezkerra (PSE-EE). Las/los parlamentarias/os de ambas formaciones participaron en el $49 \%$ del total de encuestas, siendo este porcentaje mayor al que representa su número de asientos en las cuatro cámaras objeto del estudio ${ }^{4}(25 \%$ para $\mathrm{EH}$ Bildu y $15,7 \%$ para el PSE-EE ). En cuanto a Elkarrekin Podemos (EP) y al Partido Popular (PP), apenas varió su representación en la encuesta con respecto a su presencia en las cámaras vascas (alrededor del 12\% y del 8\% respectivamente). El Partido Nacionalista Vasco (EAJ-PNV) fue el único que obtuvo una infrarrepresentación en el estudio $(30 \%)$ respecto al porcentaje real de electas y electos en los órganos legislativos vascos $(39,4 \%)$.

Algo más de la mitad de las personas encuestadas se ubicó en una franja de edad de entre 35 y 50 años (52\%). Las electas y los electos mayores de 50 años representaron el 34\% y solo el 14\% de la muestra pertenece al grupo de edad más joven (18-35 años). Podría considerarse que las respuestas obtenidas representan a un colectivo con una

\footnotetext{
${ }^{4}$ Datos referentes a la XI legislatura (2016-2020) que coincide con las fechas del estudio.
} 
experiencia política dilatada, ya que el 74\% de las personas encuestadas reconoció haber participado en el ámbito político durante más de 4 años.

En el cuestionario se invitó a los individuos de la muestra a especificar su sexo. En este apartado, los datos reflejaron una mayor participación de las mujeres. Un $42 \%$ de las participantes declaró ser mujer y un $30 \%$ indicó ser hombre. El restante $28 \%$ de la muestra prefirió no indicar un género. De este dato se deriva una doble interpretación: un mayor número de hombres declinaron participar en el estudio o un mayor número de participantes masculinos prefirieron no especificar su sexo. En todo caso, de dicha tasa de participación puede deducirse, en cierta forma, la implicación en la investigación según la variable del género de las personas participantes. En ese sentido, cabría suponer que las mujeres políticas optaron por colaborar más que sus homónimos masculinos.

Se presentan a continuación los resultados pormenorizados centrados especialmente en la opinión de las personas electas vascas sobre la manifestación pública de sus emociones, así como su opinión sobre la presencia de las emociones personales o los afectos en la retórica política general. Según lo avanzando, los resultados se organizan en dos apartados vinculados a lo que los individuos encuestados opinan sobre la expresión pública de sus emociones personales y lo que opinan sobre la presencia general de las mismas en la retórica política.

\section{RESULTADOS}

\subsection{LAS EMOCIONES PÚBLICAS DE LOS Y LAS POLÍTICAS}

La práctica totalidad de las políticas y de los políticos preguntados expone haber manifestado sus emociones, sentimientos o afectos personales ${ }^{5}$ en sus intervenciones políticas, hecho que resulta ciertamente significativo. Salvo dos representantes, la amplia mayoría indica que ocasionalmente $(45 \%)$, habitualmente $(45 \%)$ o siempre $(9 \%)$ expresa sus emociones en público. La expresión de emociones constituye, además, un recurso retórico que emplean de forma consciente para acompañar y dar coherencia al mensaje político que comunican. En ese sentido, el $68 \%$ admite haber mostrado en público sus emociones porque éstas eran acordes con el objetivo retórico de su intervención.

Por contra, esas mismas personas reconocen haber sentido en alguna interacción política el impulso, consciente o inconsciente, de disimular o reprimir sus sentimientos. Precisamente, para una de cada tres personas encuestadas esta querencia por la contención se convierte en un rasgo habitual en sus intervenciones públicas. Solo el $15 \%$ de la muestra reconoce que no reprime «nunca» sus emociones. Una de cada tres participantes admite un sentimiento de incomodidad cuando se incluyen en sus discursos alusiones a lo que sienten en primera persona.

Los foros o registros más propicios para expresar emociones son las intervenciones en mítines o actos políticos y los encuentros/charlas con militantes del partido. Nueve de cada diez personas encuestadas opina que ambos espacios son «muy propicios» o «bastante propicios». En el otro extremo se ubican tres de las actividades más frecuentes de las y los electos vascos: las intervenciones en los plenos de la institución, las ruedas de prensa y los actos institucionales. Casi ocho de cada diez políticas y políticos estiman estos foros como «poco propicios» o «nada propicios».

\footnotetext{
${ }^{5}$ Esta investigación no pretende servir a la discusión científica sobre la diferenciación entre conceptos como las emociones, los afectos o lo sentimientos. Por ello, y en aras de emplear una terminología comprensible $\mathrm{y}$ abierta, en las preguntas se hace referencia a emociones, afectos o sentimientos indistintamente, siempre con el objetivo de referirse a la misma cuestión.
} 
¿Cuáles son los motivos principales para reprimir estos elementos y por qué creen haber sentido incomodidad? La investigación otorga a estas cuestiones un carácter cualitativo e invita a las y los protagonistas del estudio a explicar abiertamente los motivos para la pulsión represiva o los sentimientos aparejados a dicha actitud.

Sobre la primera cuestión -los motivos para esconder emociones-, las palabras más repetidas por las personas encuestadas son objetividad, responsabilidad, racionalidad, prudencia, respeto, educación, incorrección, neutralidad, pudor, diplomacia, etc. Obviamente, esas palabras aluden a un determinado contexto que se inserta en un universo semántico más amplio. La interpretación de estos motivos permite deducir que las y los representantes políticos sienten que el empleo de las emociones es un recurso antagónico a la objetividad y la racionalidad, y que interfiere nítidamente en la claridad del mensaje que se quiere trasladar y en la imagen que dan las personas que participan en política («hay que cuidar la imagen y trasladar una imagen de tranquilidad», entrevistada $71)$.

Las políticas y los políticos que asumen ocultar sus emociones en público declaran que la objetividad y la racionalidad son elementos imprescindibles en su actividad política. Asimismo, para estos representantes el ser responsable, prudente, educada/o, neutral o diplomática/o debe ser reconocido como una conducta fundamental en la oratoria política, la cual es, así, considerada como antagónica de la retórica emocional en primera persona.

Por otro lado, algunas personas entrevistadas, especialmente mujeres, asimilan la muestra de emociones a actitudes de «debilidad» («siendo mujer en política te hace más débil y es una barrera para ser aceptada», entrevistada 17; «en política, se interpreta la emoción con debilidad y las mujeres nos solemos sentir muy criticadas y observadas», entrevistada 20; «Siendo una chica joven y siendo la tendencia a una cierta frialdad en política, he temido no ser aceptada si me mostraba emocional», entrevistada 34) y afirman que dicha demostración emocional es considerada como una falta de respeto al sistema democrático o al público al que representan («me reprimo porque no siempre puedes expresar todo lo que sientes, y por prudencia y respeto democrático», entrevistada 8; «porque hablamos en público y se deben guardar las formas», entrevistada/o 114).

En definitiva, las respuestas abiertas recibidas aluden a cierto carácter utilitario de las emociones, pudiéndose emplear o esconder éstas en función de cuestiones como el a) espacio donde se pronuncia el discurso, b) el tema que se trata o c) el receptor del mensaje. Las respuestas obtenidas inducen a pensar que con las emociones se debe hacer un ejercicio de contención porque es «políticamente incorrecto» (frase que se repite hasta en cuatro ocasiones): «son leyes no escritas en la política, donde los sentimientos no deben interferir» (entrevistado 86). Los argumentos para la exclusión también toman similares derroteros cuando algunas entrevistas aluden, de alguna forma, a determinados manuales de oratoria y buenas prácticas en el sistema democrático, tales como:

«La política debe ser fundamentalmente racional y neutral» (entrevistada 16). «La política no debe convertirse en lacrimógena y efectista» (entrevistado/a 42). «Las emociones pueden interferir en la claridad y el objetivo del mensaje» (entrevistada 123).

En suma, las y los electos vascos que deciden excluir sus emociones de su retórica lo hacen porque opinan que éstas deben estar ausentes del sistema político y deliberativo por los motivos que ha recogido este estudio, principalmente: objetividad, correcta argumentación, respeto a reglas de debate no escritas y a una cortesía parlamentaria, contribución al buen funcionamiento del sistema democrático, y muestra de 
responsabilidad institucional. Estos elementos están presentes en las respuestas analizadas en la parte cualitativa del estudio.

Tabla 2. Perfil de las personas entrevistadas citadas en el texto (En orden de aparición).

\begin{tabular}{|l|l|l|l|l|}
\hline Entrevistada/o & Sexo & Partido & Edad & Años en activo \\
\hline 71 & Mujer & EH Bildu & Más de 50 & Entre 4 y 10 \\
\hline 17 & Mujer & PP & $35-50$ & Más de 10 \\
\hline 34 & Mujer & EH Bildu & $18-35$ & Menos de 4 \\
\hline 20 & Mujer & EP & $35-50$ & Menos de 4 \\
\hline 8 & Mujer & PSE-EE & Más de 50 & Más de 10 \\
\hline 114 & Sin especificar & EAJ-PNV & $35-50$ & Entre 4 y 10 \\
\hline 86 & Hombre & PSE-EE & $35-50$ & Más de 10 \\
\hline 16 & Mujer & PP & Más de 50 & Más de 10 \\
\hline 42 & Sin especificar & EAJ-PNV & $35-50$ & Menos de 4 \\
\hline 123 & Mujer & EP & $35-50$ & Menos de 4 \\
\hline 44 & Hombre & EAJ-PNV & Más de 50 & Más de 10 \\
\hline 79 & Hombre & PP & $35-50$ & Más de 10 \\
\hline
\end{tabular}

\subsection{UNA MIRADA DE GÉNERO A LAS EMOCIONES PÚBLICAS}

Las encuestas obtenidas en esta investigación permiten analizar el fenómeno desde una perspectiva de género, observando si existen diferencias significativas entre mujeres electas y hombres electos en relación con la manifestación de sus emociones.

Del análisis de las respuestas obtenidas, se infiere que la implicación en el estudio es mayor en el caso de las mujeres por tres datos objetivos: responden en un mayor porcentaje, participan en mayor número en las respuestas abiertas para explicar actitudes en primera persona y ahondan más en estas explicaciones.

Como muestra la Figura 1, existe una diferencia relevante de entre 5 y 16 puntos en los porcentajes comparados entre ambos géneros en tres de las preguntas consideradas: a) la propia expresión de las emociones en sus intervenciones públicas, b) la consideración de las emociones como elementos retóricos para trasladar el mensaje y dar coherencia al acto comunicativo. y c) el tipo de sentimiento que ha producido en el actor político la propia expresión de emociones. 
Figura 1. Selección de preguntas y respuestas en torno a las actitudes de los y las electas vascas respecto a sus emociones públicas
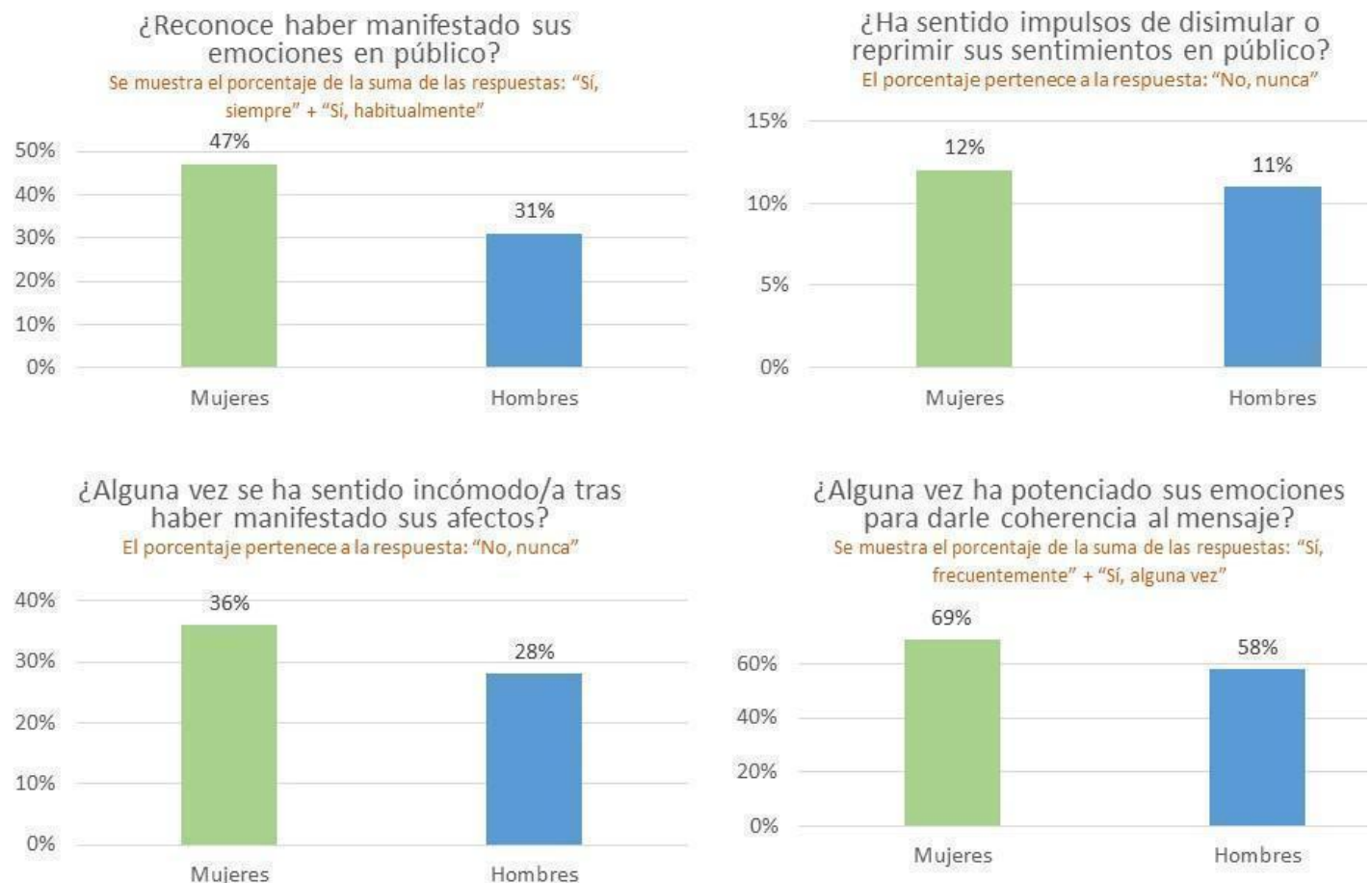

Frente a un $31 \%$ de los hombres, el $47 \%$ de las mujeres reconoce haber manifestado sus emociones, afectos, sentimientos personales o estados de ánimo en sus intervenciones políticas. Igualmente, un mayor número de mujeres admite haber empleado de manera intencional las emociones como recurso discursivo para acompañar su mensaje (69\% vs. 58\%). El porcentaje de mujeres también aumenta $(36 \%)$ respecto al de hombres $(28 \%)$ cuando se trata de reconocer un sentimiento negativo tras mostrar afectos en la actividad político-discursiva.

El porcentaje de mujeres y hombres prácticamente se iguala en el caso de aquellos y aquellas políticas que actúan en el escenario político sin disimular o reprimir sus emociones ( $12 \%$ de mujeres y $11 \%$ de hombres).

Por lo que se refiere a los motivos que llevan a la clase política a excluir las emociones de sus discursos, tal y como refleja la Figura 2, las políticas vascas y los políticos vascos no se sienten presionados por su entorno social y político. Tan solo un $5 \%$ de las mujeres y un 6\% de los hombres apuntan que o bien le han «animado a descartar ese tono», o bien les han «sugerido centrarse en argumentos políticos». Sin embargo, sí se percibe una mayor conminación desde los gabinetes o equipos de comunicación, ya que prácticamente una de cada cinco políticas y uno de cada cuatro políticos declaran que los profesionales de la comunicación les sugieren «entrarse más en argumentos políticos» o les hacen sentir que los mensajes emocionales «no tienen tanto calado político». 
Figura 2. Selección de preguntas y respuestas en torno a las actitudes de los y las electas vascas respecto a sus emociones públicas
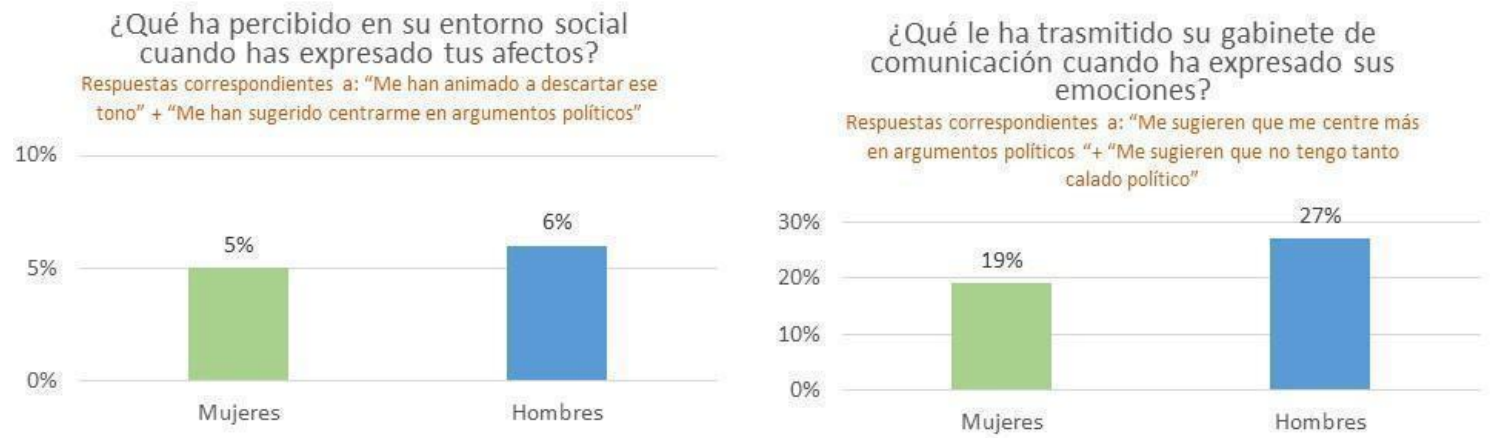

Las respuestas a preguntas abiertas resultan pertinentes para ofrecer una perspectiva de género al universo semántico que emplean unas y otros a la hora de argumentar el rechazo a la manifestación de emociones. Con aquellas respuestas de quienes reconocen haber rehuido de expresiones subjetivas sentimentales en sus discursos políticos se elaboran las Figuras 3 y 4 . En ellas se recopilan y se visualizan las palabras más representativas del conjunto de las respuestas.

Precisamente, en dichas respuestas o explicaciones abiertas en el cuestionario, mientras las políticas tienden a recurrir con mayor frecuencia al uso de la primera persona del singular, los políticos emplean en mayor medida oraciones impersonales como «lo que dicen los sentimientos no es políticamente correcto» (entrevistado 44), o «los sentimientos no deben interferir en la actividad política» (entrevistado 79).

Asimismo, las mujeres políticas tienden al empleo de conceptos como «sentimientos», «emociones» o «personal» en sus respuestas, mientras que los políticos prefieren otorgarle mayor importancia a lo considerado tradicionalmente como antagónico a la emocionalidad: la racionalidad. Además, estos tienden en mayor medida a apelar a su partido para justificar el no uso de emociones. La palabra «debate» obtiene una particular presencia en el clúster de conceptos-palabras referente al colectivo masculino, un vocablo que alude a la idea anteriormente citada de unas supuestas «normas no escritas» que deben concurrir en el debate político para que este sea considerado como positivo y constructivo.

Figura 3. Palabras clave que emplean las mujeres para responder a $\underset{6}{\mathbf{P}}$ Por qué sintió la necesidad de disimular o reprimir sus emociones?

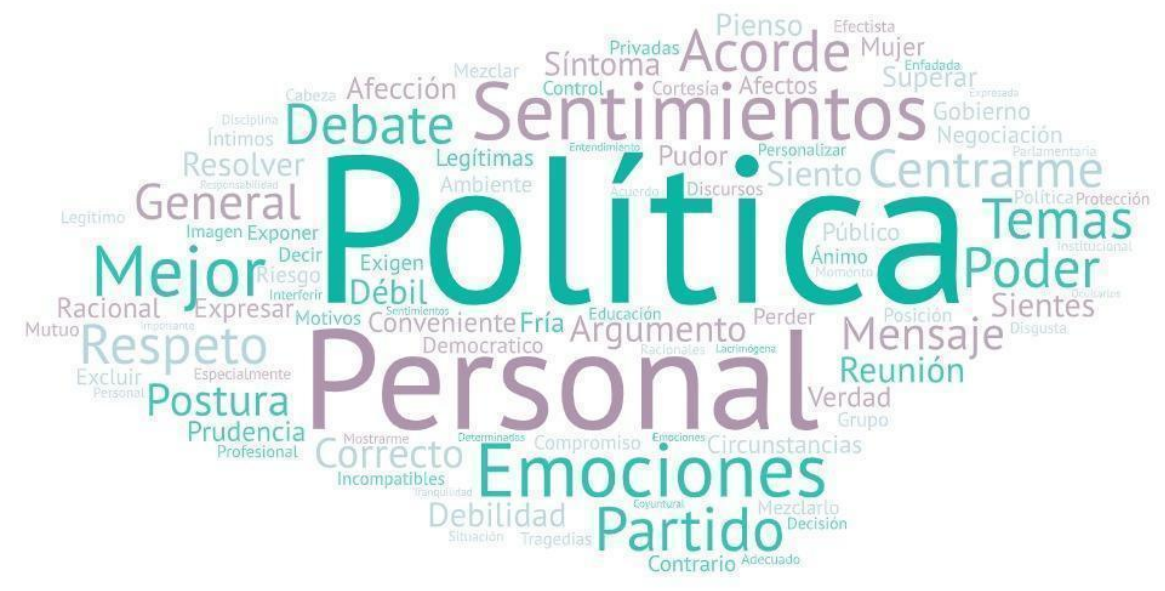


Figura 4. Palabras clave que emplean los hombres para responder a ¿Por qué sintió la necesidad de disimular o reprimir sus emociones?

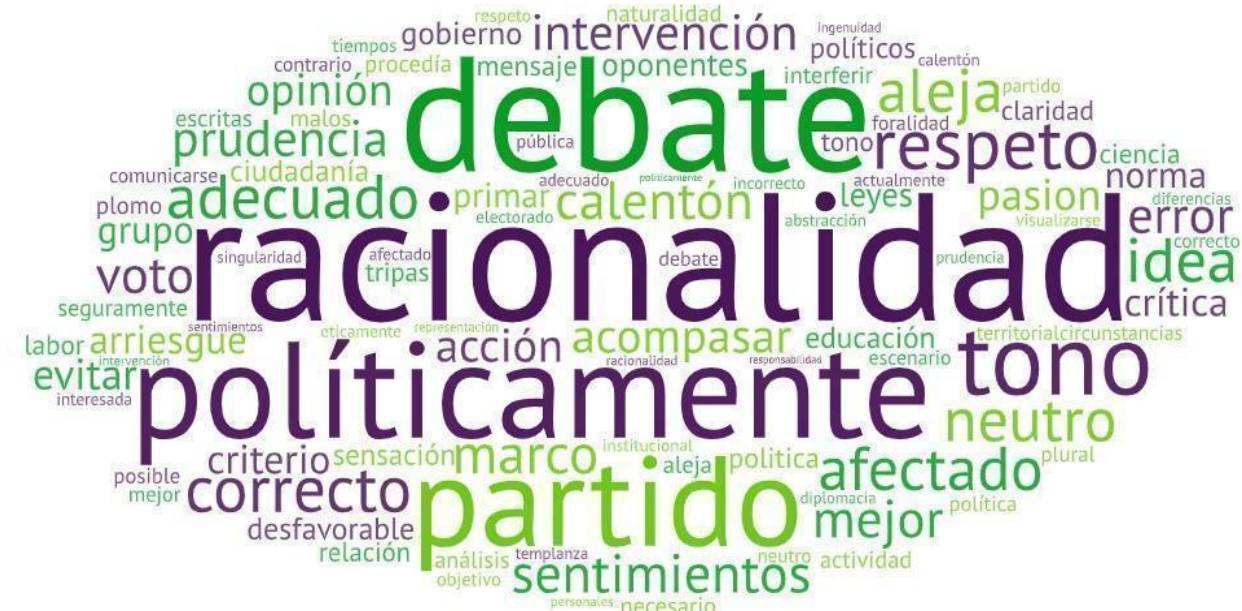

Los términos recogidos en las mencionadas respuestas abiertas sirven también para configurar la Tabla 2. Estos términos se ordenan según la lógica binaria que ha confrontado tradicionalmente a la esfera pública con la privada. Beard (2017) denomina a esta lógica de oposición referente al discurso público como «mythos masculino»y «silencio femenino». Todas las palabras fueron incluidas por las personas entrevistadas en sus respuestas, aludiendo, por un lado, a lo que debe ser aceptado en la esfera pública («mythos masculino») y, por otro, a lo que no debería mostrarse en el discurso público («silencio femenino»). En ese sentido, esta investigación ordena los conceptos con una lógica antagonista, demostrando que la mayoría de ideas se construyen en base a una dinámica de oposición implícita. Esta dinámica de oposición contribuye a construir un arquetipo de «personaje público-político» y de esfera política, aludiendo a un determinado universo semántico con los vocablos de cada columna. En la primera columna se recoge la terminología referida a lo que sí debe sí debe existir en la retórica política o el debate público. En la segunda columna se alude a lo que no debería incluirse en dicha retórica o dicho debate

Se demuestra, así, que con la propia argumentación de las personas entrevistadas se alimenta un contexto de oposición entre lo que es legítimo y lo que no es legítimo en la retórica política, lo que debe incluirse y lo que debe excluirse del discurso público y de la esfera pública, y lo que tiene cabida y lo que no tiene cabida en la práctica política.

Tabla 3. Universo semántico de oposición que refuerza la lógica binaria tradicional sobre el discurso político y el arquetipo del homo politicus ${ }^{6}$

\begin{tabular}{|c|c|}
\hline Mythos masculino & Silenciofemenino \\
\hline Objetividad & Subjetividad \\
\hline Racionalidad & Emocionalidad \\
\hline Prudencia & Imprudencia \\
\hline Fortaleza & Debilidad \\
\hline Neutralidad & Parcialidad \\
\hline
\end{tabular}

\footnotetext{
${ }^{6}$ Los espacios en blanco significan que no se ha encontrado términos antagónicos en las respuestas.
} 


\begin{tabular}{|c|c|}
\hline Razón & Pasión \\
\hline Correcto & Incorrecto \\
\hline Diplomacia & Naturalidad \\
\hline Razonamiento & Sentimiento \\
\hline Templanza & Tripas \\
\hline Plural & Personal \\
\hline Argumento & Afecto \\
\hline Legitimidad & Incompatibilidad \\
\hline Democracia & Efectismo \\
\hline Público & Íntimo \\
\hline Control & Descontrol \\
\hline Protección & Desprotección \\
\hline Tranquilidad & Exceso \\
\hline Mensaje & Interferencia \\
\hline Respeto & - \\
\hline Cabeza & - \\
\hline Compromiso & - \\
\hline Cortesía & - \\
\hline Disciplina & - \\
\hline Responsabilidad & - \\
\hline Acuerdo & - \\
\hline- & Ingenuidad \\
\hline- & Enfado \\
\hline
\end{tabular}

Este trabajo de investigación plantea también algunas cuestiones más generales en torno a la emocionalización de la esfera pública, tales como la sentimentalidad populista (Arias, 2017) o la eventual politización de lo tradicionalmente considerado como íntimo y emocional a través del discurso público-político.

Respecto a la primera cuestión, este estudio no detecta diferencias significativas en función del género de la persona entrevistada: seis de cada diez electas o electos se muestra en desacuerdo con la afirmación de que las emociones están estrechamente ligadas al populismo y pueden afectar a la democracia.

Sobre la segunda cuestión, se revela una clara divergencia entre géneros. Un 42\% de las políticas opina que la presencia de las emociones, los afectos o los sentimientos en la retórica política contribuye a mejorar el sistema. Ese porcentaje desciende hasta el $27 \%$ en el caso del género masculino. 


\section{CONCLUSIONES Y DISCUSIÓN}

Este trabajo forma parte de un proyecto más amplio que pretende complementar los resultados obtenidos con un estudio comparativo específico de los discursos en las diferentes cámaras vascas, a partir de criterios analíticos como el género y el tipo de formación política o ideológica.

A tenor de la influencia del giro afectivo en las Ciencias Sociales, este trabajo se pregunta por los motivos que llevan a los actores público-políticos a expulsar de su retórica pública las emociones, los afectos o los sentimientos personales. Todo ello en un contexto de plena pujanza de los feminismos y de aumento del número de mujeres en la vida política, mujeres que (al igual que la retórica emocional en primera persona) han sido tradicionalmente vetadas del espacio público-político a través de diversos mecanismos.

A pesar de las limitaciones que plantea un estudio de caso limitado a una determinada realidad política, se demuestra que las personas que participan en política siguen considerando que sentirse afectado por algo (que alguna circunstancia les afecte) y mostrar este hecho en público (a través de una retórica afectiva o emocional) es sinónimo de cierta debilidad «pública» ante el adversario político. La debilidad, precisamente, junto a otros atributos del sujeto filosófico como la ambigüedad o la complejidad, ha sido considerada un rasgo propio de la «naturaleza femenina» (Palacio, 2007).

Siendo cierto que la práctica totalidad de la muestra (que garantiza la pluralidad ideológica) reconoce haber recurrido a la manifestación de sus emociones en sus discursos públicos, uno de los datos más significativos demuestra que el ejercicio de contención podría ser recurrente y constante, ya que solo una minoría de las personas encuestadas reconoce no reprimir nunca sus emociones en sus discursos públicos. Este dato indica que la clase política analizada en este estudio considera sus emociones, sentimientos o afectos en primera persona ajenos o extraños en su retórica política (H1). En ese sentido, la primera hipótesis queda corroborada, quedando patente la pulsión a la represión de las emociones.

Por otro lado, no se intuye una clara apuesta por romper con el citado arquetipo tradicional del «mythos masculino» o el «hombre político», construido sobre elementos como la racionalidad, la objetividad, la prudencia, la fortaleza, la neutralidad, la razón, la templanza, etc. conceptos todos ellos que se citan en la parte cualitativa del estudio. No se vislumbra, en ese sentido, una intención franca de romper con una lógica binaria que ha fundado y legitimado históricamente ordenamientos jerárquicos en el espacio político, ni una intención de potenciar una visión renovada sobre el uso y la presencia de los afectos personales en la retórica política.

Según los datos reflejados en esta investigación pensar lo político incluyendo las experiencias personales y afectivas de los propios protagonistas del espacio político sigue siendo un objetivo lejano, aunque no inalcanzable. A ese respecto, cuatro de cada diez mujeres participantes opinan que una mayor subjetividad emocional en el espacio político contribuye a mejorar el propio sistema democrático (H2). Sobre esta cuestión, existe una relativa diferencia de género, ya que solo uno de cada cuatro hombres considera que esta vía es legítima en pos de una eventual regeneración democrática.

Este estudio deja constancia, además, de que la manifestación de las emociones en primera persona sigue siendo un acto relativamente osado para la clase política. Son una minoría de políticas y de políticas quienes otorgan un espacio sin restricciones ni obstáculos a las emociones en su discurso público, y quienes creen, además, en su poder emancipatorio. 
Mary Beard (2017) dejó patente que lo realmente emancipatorio, liberador y regenerador es que las políticas no se limiten a repetir conscientemente aspectos de la retórica masculina, porque ese tipo de prácticas contribuye a que las mujeres $-\mathrm{o}$ todas aquellas personas no representadas por el arquetipo tradicional del personaje políticosigan sintiéndose excluidas, imitadoras de papeles retóricos que sienten ajenos. En ese sentido, el «empoderamiento» de la mujer parlamentaria $-\mathrm{y}$, por extensión, de la mujer en el ámbito de la política- cabría ser repensado en el actual contexto postfeminista -al igual que ha ocurrido en otros ámbitos públicos (Gill, 2017; 2008)-, en nuestro caso, a la luz de la emocionalidad que tiende a atravesar los discursos de las parlamentarias vascas. A este respecto, dicha emocionalidad, lejos de poner en riesgo ese «empoderamiento», lo ensalza y le otorga todo su valor, en lo que podría considerarse como una auténtica revolución feminista que se gesta a escala individual y se plasma a escala colectiva (mujeres parlamentarias), significando el lema de «lo personal es político».

En suma, esta investigación explora la posibilidad de otorgar a los sentimientos o los afectos en primera persona en el discurso público y político un papel de mayor protagonismo. El mero hecho de politizar los sentimientos a través de la retórica política constituye un hecho revolucionario y un paso hacia la regeneración democrática, tal y como persiguen movimientos sociales plurales como el feminismo. Es decir, cambiar la forma de explicar la política contribuiría a reconstruir ésta a partir de otros arquetipos diferentes de los tradicionales, cambiando el propio sistema político.

\section{REFERENCIAS BIBLIOGRÁFICAS}

Ahmed, Sara. 2015. La politica cultural de las emociones. México: PUEG.

Alcaide Lara, Esperanza, Aurelia Carranza Márquez y Catalina Fuentes Rodríguez. 2016. «Emotional argumentation in Political Discourse». En A Gender-based Approach to Parliamentary Discourse: The Andalusian Parliament, coords. Catalina Fuentes Rodríguez y Gloria Álvarez Benito (pp. 129-160). Philadelphia:John Benjamins.

Alexander, Amy C., Catherine Bolzendahl y Farida Jalalzai (eds.). 2018. Measuring Women's Political Empowerment across the Globe. Strategies, Challenges and Future research. London: Palgrave Macmillan.

Álvarez Benito, Gloria, e Íñigo Mora, Isabel. 2016. «Gender differences in eye-contact behaviour in parliamentary discourse». En A Gender-based Approach to Parliamentary Discourse: The Andalusian Parliament, coords. Catalina Fuentes Rodríguez y Gloria Álvarez Benito (pp. 161-194). Philadelphia:John Benjamins.

Amorós, Celia. 1994. «Espacio público, espacio privado y definiciones ideológicas de "lo masculino" y "lo femenino"». En Feminismo, igualdad y diferencia, Celia Amorós (pp. 23-52). Recuperado en 10 de marzo de 2021 de https://emujeres.net/wp-

content/uploads/2016/08/espacio_publico_espacio_privado_definiciones_ideolo gicas_masculino_femenino_0.pdf

Arfuch, Leonor. 2016. «El "giro afectivo". Emociones, subjetividad y política». DeSignis, 24: 245-254.

Arias Maldonado, Manuel. 2016. La democracia sentimental. Barcelona: Página Indómita.

Beard, Mary. 2017. Women \& power: a manifesto. London: Profile Books.

Breeze, Ruth. 2019. «Emotion in politics: Affective-discursive practices in UKIP and Labour». Discourse \& Society 30(1): 24-43.

Butler, Judith. 1997. Mecanismos psíquicos del poder: teorías sobre la sujeción. Madrid: 
Cátedra.

Carosio, Alba. 2007. «La ética feminista: Más allá de la justicia». Revista Venezolana de Estudios de la Mujer, 12(28): 159-184.

Casas Anguita, J., José Ramón Repullo Labrador y Juan de Mata Donado Campos. 2003. «La encuesta como técnica de investigación. Elaboración de cuestionarios y tratamiento estadístico de los datos (I)». Atención primaria, 31(8): 527-538.

Clough, Patricia Tricineto, y Jean Halley (eds.), 2007. The affective turn: theorizing the social. Durham: Duke University Press.

Connell, Raewyn. 2008. Southern theory. The global dynamics of knowledge in social science. Chennai: Allen and Unwin.

De Miguel Alvarez, Ana. 2000. «Movimiento feminista y redefinición de la realidad». En Ponencia presentada en el Congreso Feminista de Córdoba, España.

Fernandes, Camila; Lemos, Mariane; Frohlich, Samantha; Esoejo, Diogo; Obara, Flávia (2020). «Women in politics: emotions and challenges in complex institutional dynamics». Cadernos EBAPE, 18: 1071-1081.

Fischer, Agneta H. (Ed.), 2000. Gender and Emotion. Social Psychological Perspectives. Paris: Cambridge University Press.

Friedan, Betty. 2009. La mística de la feminidad. 1. ${ }^{\text {a }}$ edición. Madrid: Cátedra.

Frost, Gwen. 2019. «The Subject(s) of Feminism: Gender Identity, Emotion, and Deconstruction in Contemporary Feminist Politics». WWU Honors Program Senior Projects, 139. Recuperado de https://cedar.wwu.edu/wwu_honors/139

Gill, Rosalind. 2008. «Empowerment/Sexism: Figuring Female Sexual Agency in Contemporary Advertising». Feminism \& Psychology 18(1): 35-60.

Gill, Rosalind. 2017. «The affective, cultural and psychic life of postfeminism: A postfeminist sensibility». European Journal of Cultural Studies, 20(6): 606-626.

Gorton, Kristyn. 2007. «Theorizing Emotion and Affect. Feminist engagements». Feminist Theory, 8(3): 333-348.

Gravante, Tommaso y Poma, Alice. 2015. «Las emociones como arena de la lucha política. Incorporando la dimensión emocional al estudio de la protesta y los movimientos sociales». Ciudadanía Activa, Revista Especializada en Estudios sobre la Sociedad Civil, 3(4): 17-44.

Haraway, Donna. 1995. Ciencia, ciborgs y mujeres: la reinvención de la naturaleza. Madrid: Cátedra.

Holmes, Mary. 2004. «Feeling Beyond Rules: Politicizing the Sociology of Emotion and Anger in Feminist Politics». European Journal of Social Theory, 7(2): 209-227.

Innerarity, Daniel. 2019. Politics in the Times of Indignation. The Crisis of Representative Democracy. London: Bloomsbury Academic.

Innerarity, Daniel. 2009, 4 de marzo. «El gobierno emocional». El País. Recuperado de http://www.iceta.org/di040309.pdf

Kay, Jilly Boyce. 2019. «Introduction: anger, media, and feminism: the gender politics of mediated rage». Feminist Media Studies, 19(4): 591-615.

Lara, Alí, y Domínguez, Giazu. 2013. «El giro afectivo». Athenea Digital, 13(3): 101119.

Lupton, Deborah. 1998. The emotional self: A sociocultural exploration. Londres: SAGE Publications Ltd.

Macón, Cecilia. «Género, afectos y política: Lauren Berlant y la irrupción de un dilema». Debate feminista, 49: 153-186.

Marcus, George E. 2000. «Emotions in Politics». Annual Review of Political Science, 3(1): 221-250.

Marín, R. 1985. Pedagogía Social y Sociología de la Educación. Madrid: UNED. 
Massumi, Brian. 1996. «The autonomy of affect». En Deleuze: a critical reader, ed. Paul Patton (pp. 83-109). Oxford: Blackwell.

Mora, Iñigo. 2007. «Estrategias del discurso parlamentario». Discurso \& Sociedad, 1 (3): 400-438.

Orbegozo, Julen y Larrondo, Ainara. 2019. «Lo personal es político. El Storytelling como instrumento personal y político en campaña electoral». En Comunicación, Género y Educación, eds. Juan Carlos Suárez, Sergio Marín y Paola Panarese (pp. 236242). Madrid: Dykinson.

Orgad, Shani. y Gill, Rosalind. (2019). «Safety valves for mediated female rage in the \#MeToo era». Feminist Media Studies, 19(4): 596-603.

Palacio, Marta. 2007. «Subjetividades, género y convivencia política. Cuestiones de filosofía y feminismo». En VII Jornadas de Sociología. Facultad de Ciencias Sociales, Universidad de Buenos Aires, Buenos Aires. Recuperada de https://cdsa.aacademica.org/000-106/443.pdf

Peñamarín, Cristina. 2016. «La elaboración de pasiones y conflictos en la nueva esfera pública». Designis, 24: 35-60.

Richards, Barry. 2010. «The Emotional Deficit in Political Communication». Political Communication, 21(3): 339-352.

Rubio Marín, Ruth. 2020. «Mujeres, espacio público, participación política y derechos humanos: ¿hacia un paradigma de democracia paritaria?». Revista electrónica de estudios internacionales (REEI), (39): 9.

Santesmases Mestre, Miguel Antonio. 1997. M. DYANE. Diseño y análisis de encuestas en investigación social y de mercados. Madrid: Ediciones Pirámide.

Sennett, Richard. 1977. The fall of public man. New York: Alfred A. Knopf.

Solana, Mariela, y Nayla Luz Vacarezza. 2020. «Sentimientos feministas». Revista Estudos Feministas, 28(2): 1-15.

Solomon, Robert. 1973. «Emotions and Choice». The Review of Meaphysics, 27(1): 2041.

Spivak, Gayatri Chakravorti. Amícola, José, (Tr.). 1998. «Puede hablar el sujeto subalterno?». Orbis Tertius, 3(6): 175-235.

Stanyer, James. 2013. Intimate Politics. Cambridge: Polity.

Sundström, Aksel, Pamela Paxton, Yi-Ting Wang y Staffan I. Lindberg. 2017. «Women’s political empowerment: A new global index, 1900-2012». World Development, 94, 321-335.

Thompson, Jhon B. 2011. «Los límites cambiantes de la vida pública y la privada». Comunicación y sociedad, (15): 11-42.

Velázquez García, Gabriela. 2017. «El empoderamiento político de las mujeres. La asignatura pendiente». En Seminário Internacional Fazendo Gênero 11 \& 13th Women's Worlds Congress (Anais Eletrônicos), Florianópolis. Recuperado de http://www.wwc2017.eventos.dype.com.br/resources/anais/1499457353_ARQU IVO_AvancesdelaparticipacionpoliticadelasmujeresenlaCiudaddeMexico.pdf 